\title{
Morphological Distinguish of Rupture Status between Sidewall and Bifurcation Cerebral Aneurysms
}

\author{
Caracterización Morfológica del Estado de Ruptura entre \\ Aneurismas Cerebrales en Paredes Laterales y Bifurcaciones
}

Tianlun Qiu* \& Haiyan Xing ${ }^{* * * *}$

QIU, T. \& XING, H. Morphological distinguish of rupture status between sidewall and bifurcation cerebral aneurysms. Int. J. Morphol., 32(3):1111-1119, 2014.

SUMMARY: We suspect that morphological change of two types of aneurysms in ruptured and unruptured aneurysms are distinguishing because of different location and haemodynamics. So it is necessary to discuss sidewall and bifurcation type aneurysms in ruptured and unruptured state respectively. We used 209 consecutive aneurysms (144 ruptured, 65 bifurcation type) to assess the following parameters in 3D: maximum diameter (Dmax), maximum height (Hmax), aspect ratio (AR), size ratio (SR), height/width ratio (HW), bottleneck factor (BNF, width/neck) and inflow angle (IR). These aneurysms were divided into four groups by whether ruptured and sidewall or bifurcation. 4 groups were pairwise compared by univariate analysis and some parameters with significant variation were analyzed by multinomial logistic. $\operatorname{Hmax}(\mathrm{P}=0.014)$ and $\mathrm{HW}(\mathrm{P}=0.001)$ were different significantly between ruptured bifurcation and sidewall by multinomial logistic. There was no difference between unruptured bifurcation and sidewall (P $>0.05)$ except for $\mathrm{SR}$ $(\mathrm{P}=0.002)$ by multinomial logistic. All data of ruptured aneurysms are different significantly from unruptured aneurysms $(\mathrm{P}<0.05)$ except for sidewall HW $(\mathrm{P}=0.414)$ by univariate analysis. But only $\mathrm{SR}(\mathrm{P}<0.001)$ and $\mathrm{IR}(\mathrm{P}=0.006)$ of sidewall and $\mathrm{SR}(\mathrm{P}=0.011)$ and HW $(\mathrm{P}=0.001)$ of bifurcation was significantly different by multinomial logistic. Volume of sidewall aneurysms are larger than bifurcation aneurysms and stretch characteristic of bifurcation is more obvious in ruptured aneurysms. Flow angle is the important criteria to predict fracture not in bifurcation aneurysms but in sidewall aneurysms. Size ratio is always a very important parameter to predict rupture of aneurysm no matter in bifurcation and sidewall type.

KEY WORDS: Intracranial aneurysm; Cerebral aneurysm; Risk factor; Subarachnoid hemorrhage; Morphology; Rupture.

\section{INTRODUCTION}

Aneurysms are common. Unruptured aneurysms may affect from 2 to $10 \%$ of the general population (Atkinson $e t$ al., 1989; McCormick et al., 1970; Nakagawa et al., 1994; Rinkel et al., 1998), whereas in one of the largest international studies of cerebral aneurysms to date, the International Study of Unruptured Intracranial Aneurysms (ISUIA) reported in 1998 that the cumulative rate of rupture of aneurysms that were less than $10 \mathrm{~mm}$ in diameter at diagnosis, was less than 0.05 percent per year. The risk of morbidity and mortality related to surgery greatly exceeded the 7.5-year risk of rupture among patients in the group with unruptured intracranial aneurysms smaller than $10 \mathrm{~mm}$ in diameter (No authors listed, 1998). So their identification creates a serious dilemma for neurosurgeons with regard to whether to operate on patients with incidentally discovered unruptured aneurysms, because a rupture of such an aneurysm can lead to catastrophic results. Therefore, the decision to perform preventive surgery for an unruptured aneurysm must be based on a prediction of which aneurysms are most likely to develop a rupture (Ujiie et al., 2001).

With three dimensional DSA and CT technique application on imaging of intracranial aneurysms, more detail measurements on aneurysm morphologies have become available to better assess rupture risk in diverse cerebral aneurysms. The geometrical morphological characteristics of aneurysm rupture are mostly location, shape, and size. More recently, aspect ratios greater than 1.6 have been shown to be significantly associated with rupture (Ujiie et al.). Maximum diameter, height, maximum width, bulge height, parent artery diameter, bottleneck factor, and aneurysm/ parent artery ratio were significantly $(\mathrm{P}<0.05)$ associated

* Department of Neurosurgery, Shaoxing People's Hospital, Zhejiang, China.

** School of Medicine, Shaoxing University, Zhejiang, China. 
with ruptured aneurysms (Hoh et al., 2007). Inflow-angle is also a significant discriminant of rupture status in sidewall-type aneurysms (Baharoglu et al., 2010). But the introduction of this multitude of shape parameters has also made it increasingly difficult for clinicians to assess their relative merit. This difficulty is effected by differences in patients selection bias and morphological measure based on different technique application including DSA, CTA and MRA. In addition, previous studies have analyzed saccular aneurysms in a monolithic fashion without differentiation between sidewall and bifurcation types, despite evidence of important differences in aneurysm hemodynamic patterns in these subsets (Baharoglu et al., 2012; Cebral et al., 2010).

Our current study is to eliminate this differences by a series of approaches that all clinical indexes for example age, sex, smoking, hypertension are balanced in ruptured and unruptured subsets and all morphological measures are based on catheter-based digital subtraction angiography and $3 \mathrm{D}$ rotational angiography and morphological parameters of ruptured and unruptured subsets are compared in sidewall and bifurcation types respectively because of their different location and hemodynamic patterns.

\section{MATERIAL AND METHOD}

Patient selection. Consecutive 3D angiographic data was obtained in patients with intracranial aneurysms that were diagnosed and treated from March 1, 2010 to October 31, 2013 in Shaoxing City People's Hospital (China). All Patients were diagnosed with intracranial cerebral aneurysm based on 3-dimensional DSA data confirming aneurysms and clinical information was collected from medical records including age, sex, height, weight, In particular, patient data regarding the risk factors commonly associated with aneurysm development or aneurysm rupture were noted, including smoking status, family history, history of hypertension. Patients were excluded that exhibited aneurysms that had mycotic, peripheral, fusiform, or extradural lesion characteristics or those associated with an arteriovenous malformation based on variant natural history or pathological type. Aneurysms were divided into 2 groups based on their rupture status: unruptured or ruptured aneurysm. In multiple cerebral aneurysm patients Rupture was determined based on CT data, exhibiting one or more thick areas of hemorrhage in CT scan. Additionally, daughter blebs and aspheric surfaces on DSA were used to indicate ruptured aneurysms, as previously described. The multiple cerebral aneurysms which can't be distinguished were abandoned.
Distinguish between sidewall and bifurcation types. Bifurcation aneurysms are different from sidewall aneurysms in haemodynamics. The aneurysms located at ACoA, PCoA, MCA, basilar tip or ophthalmic and anterior choroidal artery, PICA, AICA bifurcations are all defined as bifurcation aneurysms. Aneurysms growing from ICA or other cerebral artery and not connected to any bifurcations are defined as sidewall aneurysms.

Aneurysm Morphology Measurement. 3D DSA was conducted with a flat panel Allura Xper FD10 DSA unit (Philips Medical Systems, (Eindhoven, Netherlands). Measurements of the aneurysm dome, neck, and associated parent artery were performed by using the conventional angiographic images and reference markers included in the view. The patient's medical and radiologic records were reviewed and evaluated for evidence of aneurysmal intracranial hemorrhage. In patients with multiple aneurysms, clinical and radiologic information was considered and the most likely source of the hemorrhage was determined. The geometrical indices for cerebral aneurysms applied in the current study were adapted from those previously described (Lall et al., 2009). Two-dimensional (2D) measurements included: maximal diameter (Dmax), neck diameter (Dneck), aneurysm height (Hmax), maximum width (Wortho, maximal longitudinal diameter parallel with the neck plane), average parent and daughter vessel diameter $\left(\mathrm{D}_{1}, \mathrm{D}_{2}, \mathrm{D}_{3}\right)$, inflow angle (parent artery versus aneurysm apex), and dome width $\left(\mathrm{W}_{\max }\right.$, dome width perpendicular to height) (Figs. 1 and 2).

Based on these measurements, 2D indices were calculated, as follows: aspect ratio $\left(\mathrm{H}_{\max } / \mathrm{D}_{\text {neck }}\right)$, bottleneck factor (Wortho/ $\left.\mathrm{D}_{\text {neck }}\right)$, size ratio $\left(\mathrm{H}_{\max } / \mathrm{D}_{\text {parent }}\right)$, and heightwidth ratio $\left(\mathrm{H}_{\max } / \mathrm{W}_{\max }\right)$. The final measurements selected for use in statistical analyses were $\mathrm{D}_{\max }, \mathrm{H}_{\max }$, aspect ratio, bottleneck factor, size ratio, inflow angle, and height-width ratio.

Statistical analysis. The data were analyzed using SPSS version 18 for Windows (SPSS Inc., Chicago, IL). Statistical significance was assumed at $\mathrm{p}<0.05$. All aneurysms include sidewall and bifurcation types in location and ruptured and unruptured aneurysms in clinical effect. So data was divided into four groups: $\mathrm{N}^{\circ} 1$ ruptured bifurcation subset, $\mathrm{N}^{\circ} 2$ unruptured bifurcation subset, $\mathrm{N}^{\circ} 3$ ruptured sidewall subset, $\mathrm{N}^{\circ} 4$ unruptured sidewall subset. In order to eliminate the other clinical effect the age were tested independently with One-way ANOVA and sex, hypertension, Smoking were assessed with chi-square statistic among the four groups. No significant difference was tested in the age, sex, hypertension and smoking status among four groups. Because some data didn't accord with formal distribution, 

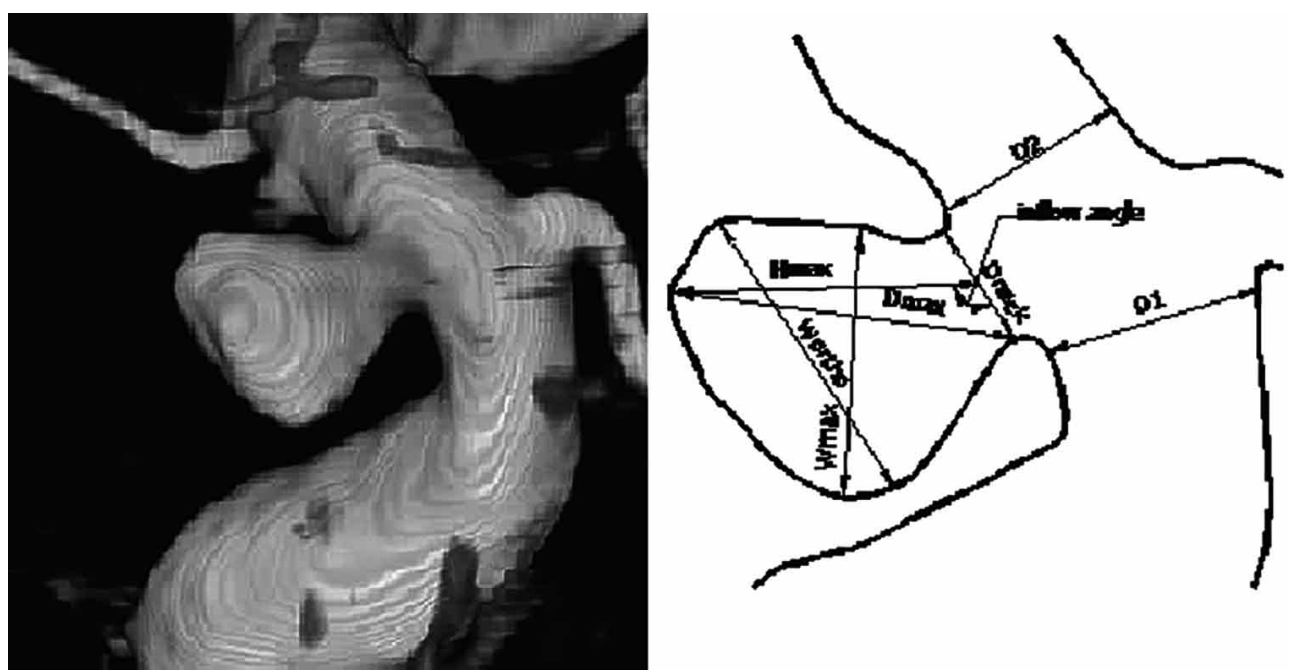

Fig. 1. Sidewall aneurysm measurements.

Maximal diameter (Dmax), longest dimension from the center of the neck to the dome tip (Hmax or Height), maximal longitudinal diameter parallel with the neck plane (Wortho), dome width perpendicular to height (Wmax), the angle between axis of flow in the parent vessel at the level of the aneurysm neck and the aneurysm's main axis from the center of the neck to the tip of the dome (inflow angle). The average value of both sides of the aneurysm neck=D1+D2/2 (average parent artery diameter).
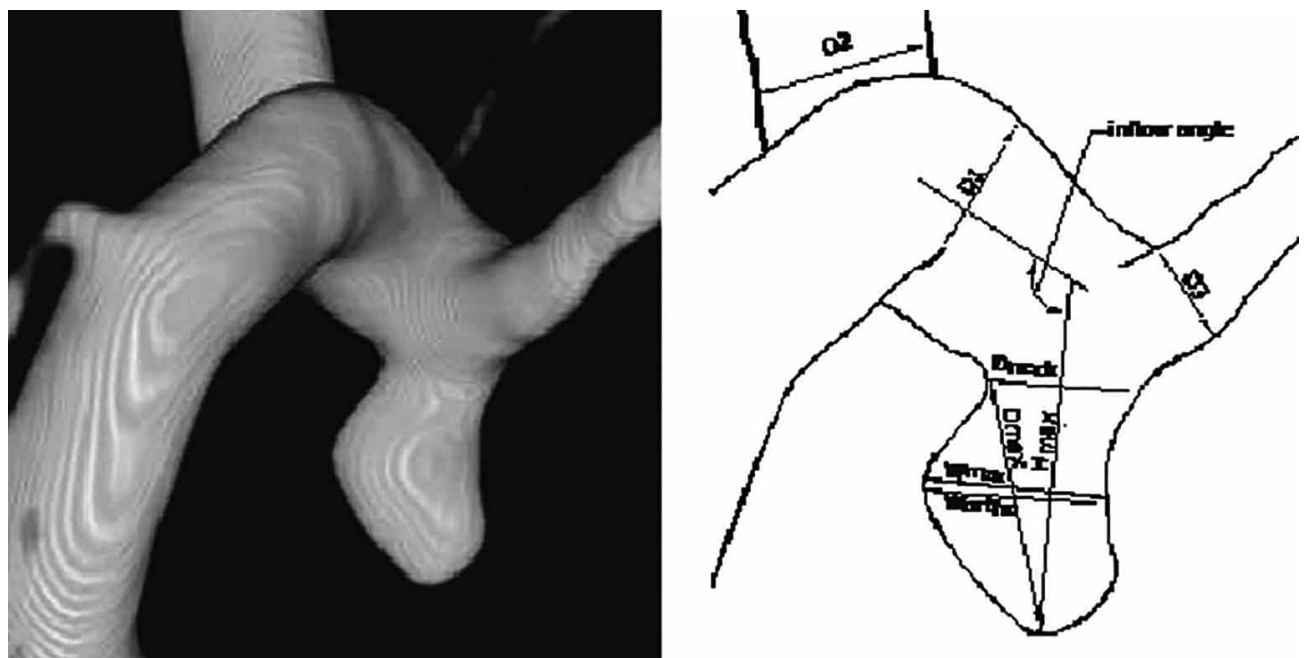

Fig. 2. Bifurcation aneurysm measurements.

Maximal diameter (Dmax), longest dimension from the center of the neck to the dome tip (Hmax or Height), maximal longitudinal diameter parallel with the neck plane (Wortho), dome width perpendicular to height (Wmax), the angle between axis of flow in the parent vessel and the aneurysm's main axis from the center of the neck to the tip of the dome (inflow angle). The average value of artery diameter $=\mathrm{D} 1+\mathrm{D} 2+\mathrm{D} 3 / 3$,

parameters had to be shown by median and $\mathrm{P}_{25}-\mathrm{P}_{75}$. All parameters had to be transformed into natural logarithm which was fit for formal distribution. Then One-way ANOVA was done in morphological data between four groups. Because of clinical demand we only compared ruptured and unruptured bifurcation aneurysms, ruptured and unruptured sidewall aneurysms, bifurcation and sidewall ruptured aneurysms, bifurcation and sidewall unruptured aneurysms.
Inflow angle wasn't compared between sidewall and bifurcation aneurysms because of their different measuring method. Multinomial logistic regression was performed separately, using forward stepwise regression to test morphological features that achieved univariate statistical significance $(\mathrm{p}<0.05)$. Box and whisker plots showed distribution of statistical significant morphological parameters for four groups. 


\section{RESULTS}

Base-line data of patients with aneurysms. Hundred seventy eight patients (mean age $55.33 \pm 11.8$ years; males: female 66:112) include 209 aneurysms. Hypertension was reported in $63(35.4 \%)$ patients. Smoking status was reported in $36(20.2 \%)$ patients. No significant difference was found in four groups with One-way ANOVA and chi-square statistic (Table I).

Data on a total of 209 aneurysms in 178 patients were analyzed. Of these aneurysms, 150 (71.8\%) were classified as bifurcation and $59(28.2 \%)$ were classified as sidewall. Table II showed the location of aneurysms. In this data, number of sidewall aneurysms were smaller than data in other papers, because PICA, AChA and OphA were included in bifurcation aneurysms for the reason of their similar morphology with ACoA and MCA (Table III).

Aneurysm Morphological Univariate Analysis and Multivariate Analysis in different location and ruptured state Four groups measurements were listed with median and $\mathrm{P}_{25}-$ $\mathrm{P}_{75}$ because some data was not fit for formal distribution (Fig. 3). After being changed into natural logarithm, parameters were compared in one-way Anova. Homogeneity of Variance of all groups were tested, Hmax, Aspact ratio and size ratio, which were equal variance, were tested by LSD and Dmax, inflow angle, bottleneck factor and height/ width ratio, which weren't equal variance, were tested by Tamhene's T2. In bifurcation aneurysms all parameters of ruptured aneurysms are larger than unruptured aneurysms significantly in univariate analysis $(\mathrm{P}<0.001)$. But only size ratio $(\mathrm{P}=0.001)$ and height/width ratio $(\mathrm{P}=0.011)$ was significantly different in multinomial logistic. In sidewall aneurysms all data of ruptured aneurysms are larger than unruptured aneurysms significantly according to univariate analysis $(\mathrm{P}<0.001)$ except for height-width ratio $(\mathrm{P}=0.414)$, because height/width ratio is closed to 1 (Median 1.12, $\mathrm{P}_{25}$ $\mathrm{P}_{75}$ 0.92-1.20) in ruptured sidewall subset, and it is closed to 1 (median $1.00 \mathrm{P}_{25}-\mathrm{P}_{75}$ 0.95-1.03) in unruptured sidewall subset also. It showed that height-width ratio of sidewall aneurysms always close to 1 no matter in ruptured or unruptured status (Table IV). At last we found that only size ration $(\mathrm{P}<0.001)$ and inflow angle $(\mathrm{P}=0.006)$ was found different significantly by multinomial logistic between ruptured and unruptured sidewall aneurysms (Table V). We found that no matter whether aneurysms was in sidewall or bifurcation, size ration was always an important parameter related to ruptured threshold. Height-width ratio was a significant parameter to judge ruptured aneurysms in bifurcation. By contrast inflow angle was significantly greater in ruptured sidewall aneurysms. Maximum height of sidewall aneurysms (Median $6.03 \mathrm{~mm}, \mathrm{P}_{25}-\mathrm{P}_{75} 4.93-10.01$ $\mathrm{mm}$ ) were larger than bifurcation type (Median $5.10 \mathrm{~mm}$, $\mathrm{P}_{25}-\mathrm{P}_{75}$ 3.74-7.19 mm) in ruptured aneurysms significantly according to univariate analysis $(\mathrm{P}=0.007)$. By contrast height/width ratio of bifurcation aneurysms (Median 1.48 mm, $\mathrm{P}_{25}-\mathrm{P}_{75}$ 1.20-1.76) were larger than sidewall subset (Median 1.12, $\mathrm{P}_{25}-\mathrm{P}_{75} 0.92-1.20$ ) in ruptured aneurysms significantly according to univariate analysis $(\mathrm{P}<0.001)$. It was confirmed in multinomial logistic $(\mathrm{P}<0.001)$ (Table V). There was no significant difference between bifurcation and sidewall type in unruptured aneurysms $(\mathrm{P}>0.05)$ except for size ration $(\mathrm{P}=0.027)$ by univariate analysis. Size ration were significantly different between bifurcation and sidewall type in unruptured aneurysms by multinomial logistic $(\mathrm{P}=0.002)$ (Table V).

Table II. Distribution of 209 aneurysms by location.

\begin{tabular}{lccc}
\hline Location & n of A neurysms & SW & BIF \\
\hline ACoA & 65 & --- & 65 \\
PICA/AChA/ OphA & 35 & --- & 35 \\
MCA & 36 & --- & 36 \\
ICAS & 40 & 40 & --- \\
BAS & 3 & 3 & --- \\
BA top & 2 & --- & 2 \\
OLS & 16 & 16 & --- \\
OLB & 12 & --- & 12 \\
Total & 209 & 59 & 150 \\
\hline
\end{tabular}

$\mathrm{ACoA}=$ anterior communicating artery; $\mathrm{ACh} A=$ anterior choroidal artery; $\mathrm{PICA}=$ posterior communicating artery; $\mathrm{Oph} \mathrm{A}=$ ophthalmic artery; $\mathrm{MCA}=$ middle cerebral artery, ICAS= internal carotid artery sidewall; BAS= Vertebrobasilar artery sidewall; BA top, tip of the basilar artery aneurysm; $\mathrm{BIF}=$ bifurcation; $\mathrm{PCA}=$ posterior cerebral artery; $\mathrm{OLS}=$ Other location sidewall, $\mathrm{OLB}=$ Other location bifurcation; $\mathrm{SW}=$ sidewall; $\mathrm{BIF}=$ bifurcation.

Table I. Basic data of in 34 patients with 76 aneurysms.

\begin{tabular}{lcccccc}
\hline \multirow{2}{*}{ Patients } & \multicolumn{4}{c}{ Groups } & \multirow{2}{*}{ Total } & \multirow{2}{*}{ p Value } \\
\cline { 2 - 5 } & $\mathbf{N}^{\mathbf{0}} \mathbf{1}$ & $\mathbf{N}^{\mathbf{0}} \mathbf{2}$ & $\mathbf{N}^{\mathbf{0}} \mathbf{3}$ & $\mathbf{N}^{\mathbf{0}} \mathbf{4}$ & & \\
\hline Age (Mean \pm SD) & $54.33 \pm 11.4$ & $56.31 \pm 9.2$ & $54.74 \pm 14.2$ & $58.26 \pm 12.7$ & $55.33 \pm 11.8$ & $P>0.05$ \\
Male: Female & $38: 64$ & $8: 14$ & $7: 12$ & $13: 22$ & $66: 112$ & $P>0.05$ \\
Hypertension & $36 / 102$ & $7 / 22$ & $9 / 19$ & $11 / 35$ & $63 / 178$ & $P>0.05$ \\
Smoking & $23 / 102$ & $4 / 22$ & $3 / 19$ & $6 / 35$ & $36 / 178$ & $P>0.05$ \\
\hline
\end{tabular}

$\mathrm{N}^{\circ} 1=$ ruptured and bifurcation subset; $\mathrm{N}^{\circ} 2=$ unruptured and bifurcation subset; $\mathrm{N}^{\circ} 3=$ ruptured and sidewall subset; $\mathrm{N}^{\circ} 4=$ unruptured and sidewall subset. One-way ANOVA and chi-square statistic showed no statistical significance in clinical effect. 
Table III. Morphological parameters in four groups.

\begin{tabular}{lcccc}
\hline \multirow{2}{*}{ Groups } & $\mathbf{N}^{\mathbf{0}}(\mathbf{n}=\mathbf{1 2 0})$ & $\mathbf{N}^{\mathbf{0}}(\mathbf{n}=\mathbf{2 6})$ & $\mathbf{N}^{\mathbf{0}}(\mathbf{n}=\mathbf{2 4})$ & $\mathbf{N}^{\mathbf{0}} \mathbf{4}(\mathbf{n}=\mathbf{3 9})$ \\
\cline { 2 - 5 } & Median $\left(\mathbf{P}_{25}-\mathbf{P}_{75}\right)$ & Median $\left(\mathbf{P}_{25}-\mathbf{P}_{75}\right)$ & Median $\left(\mathbf{P}_{25}-\mathbf{P}_{75}\right)$ & $\mathbf{M e d i a n}_{\left(\mathbf{P}_{25}-\mathbf{P}_{75}\right)}$ \\
\hline $\mathrm{D}_{\max }(\mathrm{mm})$ & $5.80(4.22-7.6)$ & $2.00(3.91-4.29)$ & $6.43(4.85-10.59)$ & $2.04(1.31-3.41)$ \\
$\mathrm{H}_{\max }(\mathrm{mm})$ & $5.10(3.74-7.19)$ & $2.20(1.97-3.19)$ & $6.03(4.93-10.01)$ & $2.00(1.40-3.00)$ \\
A spect ratio & $2.06(1.56-2.56)$ & $1.03(0.90-1.30)$ & $1.81(1.32-2.51)$ & $1.00(0.95-1.15)$ \\
Bottleneck factor & $1.64(1.29-2.10)$ & $1.02(1.00-1.26)$ & $1.46(1.11-2.35)$ & $1.00(1.00-1.16)$ \\
Size ratio & $2.67(1.90-3.50)$ & $0.98(0.79-1.20)$ & $2.36(2.01-3.58)$ & $0.80(0.56-0.90)$ \\
Inflow angle & $140.0(110.0-160.0)$ & $110.0(90.0-130.0)$ & $121.5(101.3-137.3)$ & $89.0(80.0-90.0)$ \\
Height-width ratio & $1.48(1.20-1.76)$ & $0.94(0.86-1.05)$ & $1.12(0.92-1.20)$ & $1.00(0.95-1.03)$ \\
\hline
\end{tabular}

$\mathrm{N}^{\circ} 1=$ ruptured and bifurcation subset; $\mathrm{N}^{\circ} 2=$ unruptured and bifurcation subset; $\mathrm{N}^{\circ} 3=$ ruptured and sidewall subset; $\mathrm{N}^{\circ} 4=$ unruptured and sidewall subset.

Table IV. P values from univariate analysis for morphological parameters between four groups.

\begin{tabular}{|c|c|c|c|c|}
\hline & $\begin{array}{c}N^{\circ} 1 \& N^{\circ} 2 \\
P \text { value }\end{array}$ & $\begin{array}{c}N^{\circ} 3 \& N^{\circ} 4 \\
\text { P value }\end{array}$ & $\begin{array}{c}N^{0} 1 \& N^{0} 3 \\
P \text { value }\end{array}$ & $\begin{array}{c}N^{\circ} 2 \& N^{\circ} 4 \\
P \text { value }\end{array}$ \\
\hline $\mathrm{D}_{\max }(\mathrm{mm})$ & $<0.001 *$ & $<0.001^{*}$ & 0.226 & 0.582 \\
\hline $\mathrm{H}_{\max }(\mathrm{mm})$ & $<0.001 *$ & $<0.001^{*}$ & $0.007 *$ & 0.366 \\
\hline Aspect ratio & $<0.001 *$ & $<0.001 *$ & 0.133 & 0.702 \\
\hline Bottleneck factor & $<0.001 *$ & $0.004^{*}$ & 1.000 & 1.000 \\
\hline Size ratio & $<0.001 *$ & $<0.001 *$ & 0.808 & $0.027 *$ \\
\hline Height-width ratio & $<0.001 *$ & 0.414 & $<0.001^{*}$ & 0.255 \\
\hline Inflow angle & $0.003^{*}$ & $<0.001 *$ & --- & --- \\
\hline
\end{tabular}

Table V. Evaluation of the risk factors with aneurysm by binary logistic regression analyses.

\begin{tabular}{|c|c|c|c|c|c|c|c|}
\hline Variable & & B & S.E. & Wald & $\mathbf{P}$ & OR & OR95\%CI \\
\hline \multirow[t]{3}{*}{$\mathrm{N}^{\mathrm{o}} 1 \& \mathrm{~N}^{\mathrm{o}} 2$} & Intercept & 11.665 & 2.507 & 21.651 & 0.000 & --- & --- \\
\hline & Height-width ratio & -6.501 & 1.942 & 11.204 & 0.001 & 0.002 & $0.000-0.068$ \\
\hline & Size ratio & -2.122 & 0.835 & 6.463 & 0.011 & 0.120 & $0.023-0.615$ \\
\hline \multirow[t]{3}{*}{$N^{\circ} 3 \& N^{\circ} 4$} & Intercept & -11.126 & 3.248 & 11.732 & 0.001 & --- & --- \\
\hline & Inflow angle & 0.052 & 0.019 & 7.646 & 0.006 & 1.053 & $1.015-1.093$ \\
\hline & Size ratio & 6.349 & 1.427 & 19.789 & 0.000 & 572.181 & $34.88-9386.171$ \\
\hline \multirow[t]{3}{*}{$\mathrm{N}^{\mathrm{o}} 1 \& \mathrm{~N}^{\mathrm{o}} 3$} & Intercept & 5.079 & 1.934 & 6.895 & 0.009 & --- & --- \\
\hline & $\mathrm{H}_{\mathrm{max}}$ & 1.152 & 0.468 & 6.064 & 0.014 & 3.166 & $1.265-7.921$ \\
\hline & Height-width ratio & -4.597 & 1.324 & 12.046 & 0.001 & 0.01 . & $0.001-0.135$ \\
\hline \multirow[t]{2}{*}{$\mathrm{N}^{\mathrm{o}} 2 \& \mathrm{~N}^{\mathrm{o}} 4$} & Intercept & -4.540 & 3.001 & 2.288 & 0.130 & --- & --- \\
\hline & Size ratio & 4.342 & 1.374 & 9.982 & 0.002 & 76.852 & $5.199-1136.084$ \\
\hline
\end{tabular}

\section{DISCUSSION}

Morphological parameters are important index to predict which aneurysms will rupture and which will not. Different data have been reported to predict rupture of aneurysms, but many of them are contradictory and unbalanced. For example although aneurysm size is theoretically and empirically an important predictor for the occurrence of SAHs, the critical size for a rupture remains controversial. Wiebers et al., (1987) described the identification of a critical size of $10 \mathrm{~mm}$, below which no aneurysm had ruptured. The ISUIA showed a near-zero rupture risk of $0.05 \%$ per year for aneurysms smaller than $10 \mathrm{~mm}$ indiameter (No authors listed). Many other neurosurgeons, however, have observed aneurysms smaller than $10 \mathrm{~mm}$ that bled (Beck et al., 2006; Forget et al., 2001; Yasui et al., 1996). Schievink et al. (1992) reported three cases of aneurysmal rupture in patients with previously documented unruptured aneurysms smaller than $5 \mathrm{~mm}$. Juvela et al. (1993) reported that of the aneurysms that later 

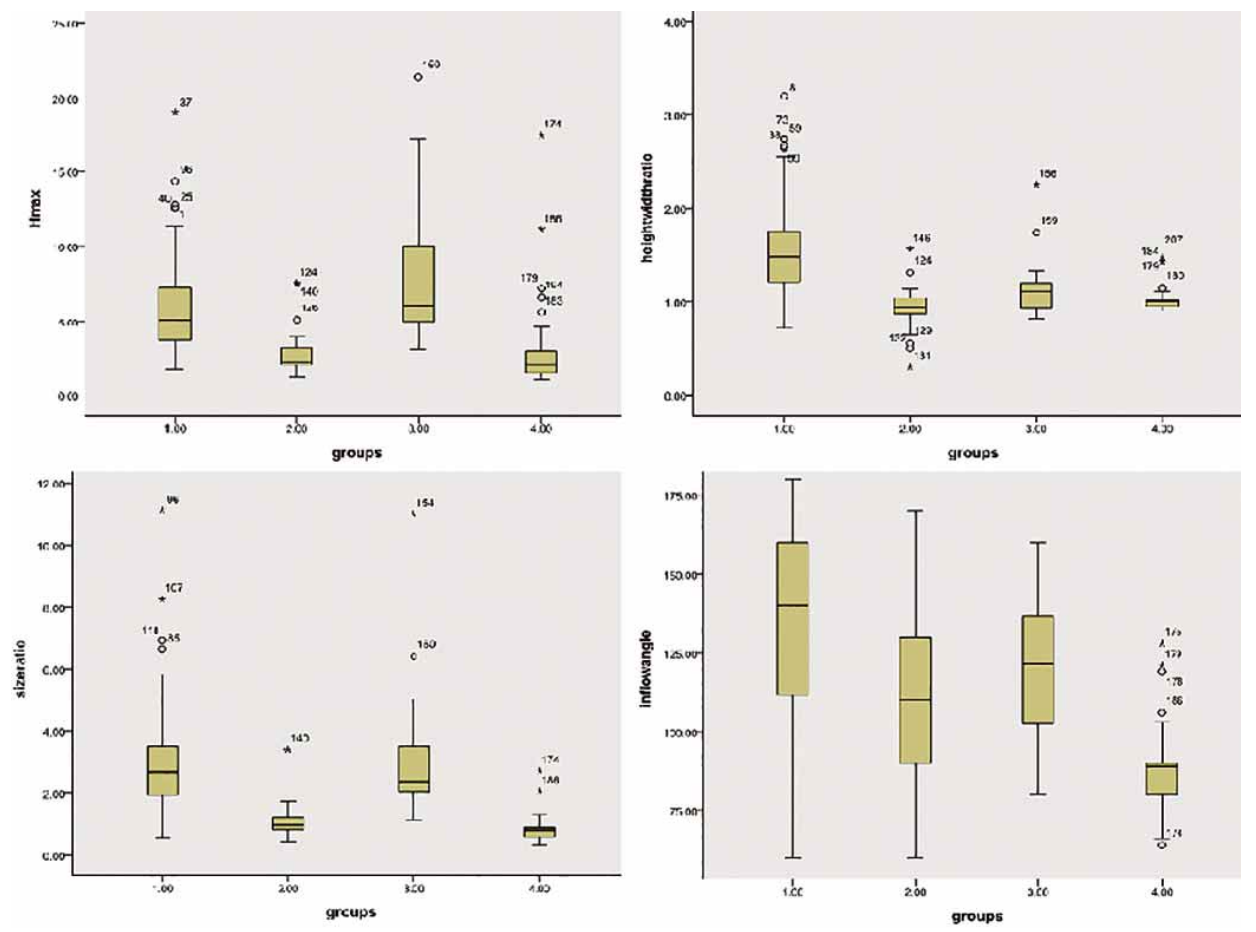

Fig. 3. Box and whisker plots showing distribution of Hmax, inflow angle, and height/ width, size ratio for four groups.

ruptured, $67 \%$ were smaller than $6 \mathrm{~mm}$. Many other morphological parameters are in the same argument (Amenta et al., 2012; Ishibashi et al., 2009; Lin et al., 2012; Ryu et al., 2011; Ujiie et al.).

Why these studies are inconsistent, we knew that possible patient-level confounding variables such as history of smoking, history of hypertension, or even genetic predisposition are important causes. To avoid these confounding variables we must ensure that no significant difference was found in compared groups. Aneurysm location is the more important factor to confound morphological ruptured parameters. Ishibashi et al., reported that posterior circulation aneurysms were significant risk factors for prediction of rupture of unruptured intracranial saccular aneurysms. But we consider that formation and progress of aneurysms attribute to haemodynamic effect between aneurysms and parent arteries. So their relative location is very much important. We can distinguish bifurcation and sidewall type by aneurysm location as has been discussed (Baharoglu et al., 2012). In this data maximum height $(\mathrm{P}=0.007)$ and height-width ratio $(\mathrm{P}<0.001)$ are different significantly between bifurcation and sidewall ruptured aneurysms by univariate analysis. It is interesting that maximum height in sidewall aneurysms (Median 6.03 $\mathrm{mm}, \mathrm{P}_{25}-\mathrm{P}_{75} 4.93-10.01 \mathrm{~mm}$ ) were larger than that in bifurcation aneurysms (Median $5.10 \mathrm{~mm}, \mathrm{P}_{25}-\mathrm{P}_{75} 3.74-7.19$ $\mathrm{mm}$ ) in ruptured aneurysms, but height/width ratio in bifurcation type (Median 1.48, $\mathrm{P}_{25}-\mathrm{P}_{75} 1.20-1.76$ ) were larger than sidewall aneurysms (Median 1.12, $\mathrm{P}_{25}-\mathrm{P}_{75} 0.92-1.20$ ) in ruptured aneurysms significantly. There were no difference between unruptured bifurcation and sidewall aneurysms $(\mathrm{P}>0.05)$ except for size ratio $(\mathrm{P}=0.027)$ by univariate analysis. It is confirmed by multinomial logistic $(\mathrm{P}=0.002)$. It is strange that size ration of unruptured sidewall aneurysms (Median $\left.0.80, \mathrm{P}_{25}-\mathrm{P}_{75} 0.56-0.90\right)$ is smaller than unruptured bifurcation aneurysms (Median $0.98, \mathrm{P}_{25}-\mathrm{P}_{75} 0.79-1.20$ ). Forty aneurysms grew from internal carotid in all 59 sidewall aneurysms in which many aneurysms were unruptured and small in our data. In fact we can always see these small unruptured aneurysms in the internal carotid, which lead to smaller size ratio. All parameters of ruptured aneurysms are larger than unruptured aneurysms significantly in univariate analysis $(\mathrm{P}<0.01)$ except for height-width ratio in sidewall type $(\mathrm{P}=0.414)$. That means aneurysms can "grow" from the unruptured to the ruptured. So we need to observe aneurysms dynamically. Early aneurysms are only a bubble from artery, so their shape and morphological parameters are similar regardless if in bifurcation and sidewall. But they grow in different morphological character owing to bifurcation and sidewall. Height-width ratio means the stretch of aneurysm. Then we can see ruptured bifurcation aneurysms stretch more than ruptured sidewall aneurysms. But sidewall aneurysms can grow larger than bifurcation aneurysms until they 
rupture. It may be the result of different haemodynamic effect. The growth of aneurysms is caused by wall shear stress (WSS). WSS is the tangential force produced by blood moving across the endothelial surface; the impingement region is the region with collision between the inflow jet and the aneurysm wall. The blood flow stream might have made direct contact with the aneurysmal dome in bifurcation aneurysms and most of the necks are on the central axis of the parent artery. The impingement region was small. On the contrary the direction of the blood flow might be changed around the neck and then reach the aneurysmal dome in sidewall aneurysms. Thus, this process might decrease the impact of the blood flow on the dome. The impingement region was relatively larger. This is in line with the results of Cebral et al. (2005, 2010), which showed that $77 \%$ of blebs were overlapped with or adjacent to the inflow jet. Localized, extraordinarily high WSS caused by a very concentrated inflow jet is thought to have damaging effects on the arterial wall, to which a chronic exposure might cause the development of aneurysmal daughter blebs. Regional dome can get higher WSS in bifurcation aneurysms than sidewall aneurysms and bifurcation aneurysms may have more unbalanced WSS than sidewall aneurysms. So sidewall aneurysms look like more sphere than bifurcation aneurysms. The unbalanced WSS distribution and its spatial gradient (WSSG) may lead to earlier rupture of bifurcation aneurysms than sidewall aneurysms and we can see there were significant difference between bifurcation aneurysm height and sidewall aneurysms height. The unbalanced WSS distribution and WSSG may also lead to unbalanced grow of aneurysms that was regarded as stretch of aneurysm, which was quantized by height-width ratio. In bifurcation type though Dmax, Hmax, aspect ratio, bottleneck factor, size ratio, inflow angle, and height-width ratio in ruptured aneurysms were all larger than unruptured aneurysms, but only height-width ratio and size ratio were different significantly in multinomial logistic, which means heightwidth ratio that represents stretch of aneurysm is a very important indicator that predicts the rupture of bifurcation aneurysms. Sidewall aneurysms have less WSS and larger impingement region relative to bifurcation aneurysms. So the ruptured bifurcation aneurysms had larger maximum height relative to bifurcation aneurysms, which means they can grow larger than bifurcation aneurysms.

It needs to be emphasized that size ratio is different significantly between ruptured and unruptured aneurysms by multinomial logistic whether in bifurcation aneurysms or in sidewall aneurysm, though other size parameters for example Dmax and Hmax, aspect ratio and bottleneck factor are also different significantly in univariate analysis. Carter et al. (2006), reported that the distribution of aneurysm sizes differs according to location in the intracranial vasculature in this single institution series. Smaller aneurysm sizes are observed for distal aneurysms than at other locations in the Circle of Willis. They hypothesize that this may be related to Laplace's Law, which states that the critical size for aneurysm rupture is related to the parent artery wall thickness. The conclusion coincided with our results that criterion of which aneurysms will rupture is not only based on absolute size, the size of aneurysm relative to its parent artery is the more important factor.

Baharoglu et al. (2010), reported that Increasing WSS may promote expand of sidewall aneurysms. Computational fluid dynamic analysis showed increasing inflow angle (IA) leading to deeper migration of the flow recirculation zone into the aneurysm with higher peak flow velocities and a greater transmission of kinetic energy into the distal portion of the dome. Increasing IA resulted in higher inflow velocity and greater wall shear stress magnitude and spatial gradients in both the inflow zone and dome. We found that in sidewall type inflow angle of ruptured aneurysms (Median $121.5^{\circ}$, $\left.\mathrm{P}_{25}-\mathrm{P}_{75} 101.3^{\circ}-137.3^{\circ}\right)$ was larger significantly than inflow angle of unruptured aneurysms (Median 89.0, $\mathrm{P}_{25}-\mathrm{P}_{75} 80.0^{\circ}-$ $90.0^{\circ}$ ). It was ensured by multinomial logistic regression analyses $(\mathrm{P}=0.006)$. Though inflow angle of ruptured aneurysms (Median $140^{\circ}, \mathrm{P}_{25}-\mathrm{P}_{75} 110.0^{\circ}-160.0^{\circ}$ ) was also larger significantly than inflow angle of unruptured aneurysms $\left(110.0^{\circ}, 95 \%\right.$ CI $\left.90.0^{\circ}-130.0^{\circ}\right)$ in bifurcation type. The difference wasn't significant by multinomial logistic regression. Compared with bifurcation type, inflow angle plays a more important role in sidewall type apparently. We suppose that bifurcation aneurysms and its parent arteries have more complicated morphological relation, inflow angle can't affect its WSS fatefully. The result was consistent with Baharoglu's study.

Analysis of aneurysm shape to identify rupture status discriminants depends on the hypothesis that aneurysm shape does not change after rupture. The current analysis may not judge if aneurysm shape changes significantly after rupture. Even though increasing evidence indicates that such a change does not occur (Asari \& Ohmoto, 1993; Rahman et al., 2011), conclusive data on this subject remain scant. The present analysis is retrospective in character and thus can only imply prediction of previously determined rupture status. The conclusions of this study require validation in prospective randomized studies before their performance can be validated and applied in risk assessment of the incidentally found unruptured aneurysm in clinical practice. Finally, the current study describes relatively small data (209 aneurysms). Additional data from larger multicenter studies should be pooled and analyzed both retrospectively and prospectively to minimize the inherent bias and distribution imbalance. 


\section{CONCLUSION}

We need to consider aneurysms dynamically because aneurysms can grow spontaneously with blood flow lash. Aneurysms may grow with different shape because of different location and relation with parent arteries. Bifurcation and sidewall type are the most popular method to distinguish different blood flow dynamics. Blood flow impact gives rise to rupture of aneurysms. So it is necessary to discuss relationship between aneurysm morphometry and ruptured status in Bifurcation and sidewall type respectively. We found that bifurcation and sidewall type in ruptured aneurysms have different shape that volume of sidewall aneurysms are larger than bifurcation aneurysms because they have less WSS and larger impingement region relative to bifurcation aneurysms. But stretch characteristic which is expressed by height/width ratio is more obvious in bifurcation aneurysms, sidewall aneurysms more close to sphere. In our study, unruptured aneurysms include many initial and small aneurysms. Morphology of two types is very similar in unruptured aneurysms except for size ratio because of different location. In bifurcation type stretch character of ruptured aneurysms which is embodied by height/width ratio is very different from unruptured aneurysms. But in sidewall type stretch character of ruptured aneurysms isn't obvious. Flow angle in sidewall aneurysms is an important criteria with which the aneurysm may rupture, but it does not apply to bifurcation aneurysms because it has more complicated blood flow dynamics. Size ratio is always a very important parameter to predict rupture of aneurysm no matter in bifurcation and sidewall type.

QIU, T. \& XING, H. Caracterización morfológica del estado de ruptura entre aneurismas cerebrales en paredes laterales y bifurcaciones. Int. J. Morphol., 32(3):1111-1119, 2014.

RESUMEN: Sospechamos que el cambio morfológico de dos tipos de aneurismas, con y sin ruptura, son distinguibles por diferencias en su hemodinamia y ubicación. Por esto, es necesario discutir sobre el estado de ruptura en los aneurismas ubicados en una pared lateral o bifurcación, respectivamente. Utilizamos 209 aneurismas consecutivos (144 con ruptura y 65 de bifurcación) para evaluar los siguientes parámetros en tres dimensiones: diámetro máximo (Dmax), altura máxima (Amax), relación de aspecto (RA), relación de tamaño (RT), relación de altura/ancho (AA), factor de cuello de botella (FCB, ancho/cuello) y ángulo de entrada (AE). Los aneurismas se dividieron en cuatro grupos por su estado de ruptura (rotos y no rotos) y ubicación (pared lateral y bifurcación). Los grupos se compararon por pares mediante análisis univariado y quienes presentaran variación significativa fueron analizados por logística multinomial. La Amax $(\mathrm{P}=0,014)$ y AA $(\mathrm{P}=0,001)$ mostraron diferencias significativas entre aneurismas con ruptura en bifurcación y pared lateral, según la logística multinomial. No hubo diferencias entre los aneurismas sin ruptura en bifurcación y pared lateral $(\mathrm{P}>0,05)$, excepto para $\mathrm{RT}(\mathrm{P}=0,002)$ por logística multinomial. Todos los datos de aneurismas con ruptura mostraron diferencias significativas con los sin ruptura $(\mathrm{P}<0,05)$, excepto para la AA en la pared lateral $(\mathrm{P}=0,414)$ según el análisis univariado. Sólo las $\mathrm{RT}(\mathrm{P}<0,001)$ y $\mathrm{AE}(\mathrm{P}=0,006)$ de la pared lateral, y RT $(\mathrm{P}=0,011)$ y AA $(\mathrm{P}=0,001)$ en bifurcación tuvieron diferencias significativas mediante logística multinomial. El volúmen de los aneurismas de pared lateral fue mayor que los de bifurcación, así como la ruptura fue más evidente en el tramo característico de la bifurcación. El AE es un criterio importante para predecir la rotura en los aneurismas de pared lateral. La RT siempre es un parámetro importante para predecir la rotura de un aneurisma, tanto para los que ocurren en bifurcación y en la pared lateral.

PALABRAS CLAVE: Aneurisma intracraneal; Aneurisma cerebral; Factor de riesgo; Hemorragia subaracnoidea; Morfología; Ruptura.

\section{REFERENCES}

Amenta, P. S.; Yadla, S.; Campbell, P. G.; Maltenfort, M. G.; Dey, S.; Ghosh, S.; Ali, M. S.; Jallo, J. I.; Tjoumakaris, S. I.; Gonzalez, L. F.; Dumont, A. S.; Rosenwasser, R. H. \& Jabbour, P. M.Analysis of nonmodifiable risk factors for intracranial aneurysm rupture in a large, retrospective cohort. Neurosurgery, 70(3):693-9, 2012.

Asari, S. \& Ohmoto, T. Natural history and risk factors of unruptured cerebral aneurysms. Clin. Neurol. Neursurg., 95(3):205-14, 1993.

Atkinson, J. L.; Sundt, T. M. Jr.; Houser, O. W. \& Whisnant, J. P. Angiographic frequency of anterior circulation intracranial aneurysms. J. Neurosurg., 70(4):551-5, 1989.
Baharoglu, M. I.; Schirmer, C. M.; Hoit, D. A.; Gao, B. L. \& Malek, A. M. Aneurysm inflow-angle as a discriminant for rupture in sidewall cerebral aneurysms: morphometric and computational fluid dynamic analysis. Stroke, 41(7):1423-30, 2010.

Baharoglu, M. I.; Lauric, A.; Gao, B. L. \& Malek, A. M. Identification of a dichotomy in morphological predictors of rupture status between sidewall- and bifurcation-type intracranial aneurysms. J. Neurosurg., 116(4):871-81, 2012.

Beck, J.; Rohde, S.; Berkefeld, J.; Seifert, V. \& Raabe, A. Size and location of ruptured and unruptured intracranial aneurysms measured by 3-dimensional rotational angiography. Surg. Neurol., 65(1):18-25, 2006. 
Carter, B. S.; Sheth, S.; Chang, E.; Sethl, M. \& Ogilvy, C. S. Epidemiology of the size distribution of intracranial bifurcation aneurysms: smaller size of distal aneurysms and increasing size of unruptured aneurysms with age. Neurosurgery, 58(2):217-23, 2006.

Cebral, J. R.; Castro, M. A.; Burgess, J. E.; Pergolizzi, R. S.; Sheridan, M. J. \& Putman, C. M. Characterization of cerebral aneurysms for assessing risk of rupture by using patientspecific computational hemodynamics models. AJNR Am. J. Neuroradiol., 26(10):2550-9, 2005.

Cebral, J. R.; Sheridan, M. \& Putman, C. M. Hemodynamics and bleb formation in intracranial aneurysms. AJNR Am. J. Neuroradiol., 31(2):304-10, 2010.

Forget, T. R. Jr.; Benitez, R.; Veznedaroglu, E.; Sharan, A.; Mitchell, W.; Silva, M. \& Rosenwasser, R. H. A review of size and location of ruptured intracranial aneurysms. Neurosurgery, 49(6):1322-6, 2001

Hoh, B. L.; Sistrom, C. L.; Firment, C. S.; Fautheree, G. L.; Velat, G. J.; Whiting, J. H.; Reavey-Cantwell, J. F. \& Lewis, S. B. Bottleneck factor and height-width ratio: association with ruptured aneurysms in patients with multiple cerebral aneurysms. Neurosurgery, 61(4):716-22, 2007.

Ishibashi, T.; Murayama, Y.; Urashima, M.; Saguchi, T.; Ebara, M.; Arakawa, H.; Irie, K.; Takao, H. \& Abe, T. Unruptured intracranial aneurysms: incidence of rupture and risk factors. Stroke, 40(1):313-6, 2009.

Juvela, S.; Porras, M. \& Heiskanen, O. Natural history of unruptured intracranial aneurysms: a long-term follow-up study. $J$. Neurosurg., 79(2):174-82, 1993.

Lall, R. R.; Eddleman, C. S.; Bendok, B. R. \& Batjer, H. H. Unruptured intracranial aneurysms and the assessment of rupture risk based on anatomical and morphological factors: sifting through the sands of data. Nerosurg. Focus, 26(5):E2, 2009.

Lin, N.; Ho, A.; Gross, B. A.; Pieper, S.; Frerichs, K. U.; Day, A. L. $\& \mathrm{Du}, \mathrm{R}$. Differences in simple morphological variables in ruptured and unruptured middle cerebral artery aneurysms. $J$. Neurosurg., 117(5):913-9, 2012.

McCormick, W. F. \& Acosta-Rua, G. J. The size of intracranial saccular aneurysms. An autopsy study. J. Neurosurg., 33(4):422-7, 1970.

Nakagawa, T. \& Hashi, K. The incidence and treatment of asymptomatic, unruptured cerebral aneurysms. J. Neurosurg., 80(2):217-23, 1994.

No authors listed. Unruptured intracranial aneurysms--risk of rupture and risks of surgical intervention. International Study of Unruptured Intracranial Aneurysms Investigators. N. Engl. J. Med., 339(24):1725-33, 1998.
Rahman, M.; Ogilvy, C. S.; Zipfel, G. J.; Derdeyn, C. P.; Siddiqui, A. H.; Bulsara, K. R.; Kim, L. J.; Riina, H. A.; Mocco, J. \& Hoh, B. L. Unruptured cerebral aneurysms do not shrink when they rupture: multicenter collaborative aneurysm study group. Neurosurgery, 68(1):155-60, 2011.

Rinkel, G. J.; Djibuti, M.; Algra, A. \& van Gijn, J. Prevalence and risk of rupture of intracranial aneurysms: a systematic review. Stroke, 29(1):251-6, 1998.

Ryu, C. W.; Kwon, O. K.; Koh, J. S. \& Kim, E. J. Analysis of aneurysm rupture in relation to the geometric indices: aspect ratio, volume, and volume-to-neck ratio. Neuroradiology, 53(11):883-9, 2011.

Schievink, W. I.; Piepgras, D. G. \& Wirth, F. P. Rupture of previously documented small asymptomatic saccular intracranial aneurysms. Report of three cases. J. Neurosurg., 76(6):1019-24, 1992.

Ujiie, H.; Tamano, Y.; Sasaki, K. \& Hori, T. Is the aspect ratio a reliable index for predicting the rupture of a saccular aneurysm? Neurosurgery, 48(3):495-502, 2001.

Wiebers, D. O.; Whisnant, J. P.; Sundt, T. M. Jr. \& O’Fallon, W. M. The significance of unruptured intracranial saccular aneurysms. J. Neurosurg.,66(1):23-9, 1987.

Yasui, N.; Magarisawa, S.; Suzuki, A.; Nishimura, H.; Okudera, T. \& Abe, T. Subarachnoid hemorrhage caused by previously diagnosed, previously unruptured intracranial aneurysms: a retrospective analysis of 25 cases. Neurosurgery, 39(6):1096100, 1996.

\section{Correspondence to: \\ Tianlun Qiu \\ Department of Neurosurgery \\ Shaoxing City People's Hospital \\ Shaoxing 312000 \\ Zhejiang Province \\ CHINA}

Tel: +86-13676884796

Fax: +86-21-64085875

Email: tianlunqiu@163.com

Received: 09-12-2013

Accepted: 27-06-2014 